Article Citation Format

Chukwuedo, J.A. (2019): Analysis of Domestic Energy Usage for Electrical Appliances in a Nigerian Metropolitan Area. Journal of Digital Innovations \& Contemp Res. In Sc., Eng \& Tech. Vol. 7, No. 1. Pp 43-58

Article Progress Time Stamps
Article Type: Research Article
Manuscript Received: $8^{\text {th }}$ March. 2019
Review Type: Blind
Final Acceptance:: $18^{\text {th }}$ March, 2019
Article DOI: dx.doi.org/10.22624/AIMS/DIGITAL/V7N1P5

$\underline{\text { Article Progress Time Stamps }}$

Article Type: Research Article

Review Type: Blind

Final Acceptance:: $18^{\text {th }}$ March, 2019

Article DOI: dx.doi.org/10.22624/AIMS/DIGITAL/V7N1P5

\title{
Analysis of Domestic Energy Usage for Electrical Appliances in a Nigerian Metropolitan Area.
}

\author{
Chukwuedo, J.A. \\ Department of Chemical Engineering Technology \\ Delta State Polytechnic \\ Ogwashi-Uku, Delta State, Nigeria. \\ E-mail: Justjo204@gmail.com \\ Phone: +2348037581944
}

\begin{abstract}
A research was conducted on energy usage in Owerri metropolitan area. Energy consumption survey was done using questionnaires. Classification was made into low, medium and high income earners in order to determine domestic energy consumption in appliances. To analyse the various sources of energy available for domestic use in appliances and know which is more economical, a model equation was used and $\mathrm{R}^{2}$ value of 0.9516 for domestic appliances were obtained, which is an indication of goodness of fit of the model. It also predicts that there was a strong interaction between the source of power and level of income of the populace. It also predicts that in domestic appliances the low income earners spent least using diesel while the high income earners spent most using petrol.
\end{abstract}

Key words: Analysis, Appliances, Consumption, Domestic, Energy, Electricity, Metropolitan and Usage.

\section{BACKGROUND INFORMATION}

Energy is one of the basic requirements of human societies. It is vital for human life and technology advancement. In general energy can contribute to widening opportunities and it empowers people to exercise choices. The demand for energy today is far greater than ever in our highly technological world. It is a well known fact that the high rate of industrial growth of any country is a function of the amount of energy available in that country and the extent to which this energy is utilized. (Nigeria Energy Study, 2005)

\section{PROBLEM STATEMENT}

While the world works towards the use of cleaner energy our priority should be to use the energy we generate more efficiently. The major challenge has been that energy policy in Nigeria has undermined the importance and gain of energy efficiency to the environment and economic growth. 
Efficiency is not only cheaper than all other options; it also leads to growth in jobs and personal income (Nnaji et al.2012). Predicting energy usage with model equation in order to know which source is more economical is hereby looked into.

\section{OBJECTIVES OF THE RESEARCH}

The aim of the research is to study the pattern of energy usage domestically and industrially in Owerri metropolitan area, an urban city in south eastern Nigeria.

The objectives of the study are:

$1 \quad$ To identify the major energy sources in use

2 To determine the level of consumption of the energy sources

3 To identify lapses in energy use.

$4 \quad$ To identify renewable energy potentials in the region and Nigeria in general.

$5 \quad$ To identify which source of energy is more economical and environmental friendly.

\section{MATERIALS AND METHODS}

\subsection{Study area.}

Household energy consumption survey was carried out in Owerri , Nigeria. Owerri lies within latitudes $5^{0}$ $.29^{\prime} \mathrm{N}$ and $5.485^{\circ} \mathrm{N}$, and longitude $7^{\circ} .02^{\prime} \mathbf{E}$ and $7.035^{\circ} \mathbf{E}$. It is the capital of Imo state in Nigeria, set in the heart of the Igboland. It consists of three local government areas including Owerri municipal, Owerri North and Owerri West. It had an estimated population of about 400,000 as at 2006 census and is approximately 40 square miles $\left(100 \mathrm{~km}^{2}\right)$ in area. Owerri is bordered by the Otamiri River to the east and the Nworie River to the south (www.ngex.com).

\subsection{Materials}

A household energy survey was conducted to elicit information on the pattern of energy consumption for domestic cooking, domestic lightening and domestic appliances during the period of October 2015 to March 2016. The household questionnaire comprised two main parts: first part consisted of questions addressing the socio-economic characteristics of the respondents and households sampled. This then enabled me to classify them into low income, medium and high income earners, while second part consisted of questions which addressed the pattern of energy used for cooking, appliances and lighting.

\subsection{Method of data collection}

I made use of questionnaires to obtain responses from households in the metropolis; the questionnaire is exact, simple and objective, covering issues relating to the subject matter. The questionnaire was administered by hand. A total of 120 questionnaire forms were administered in a random sampling method with 108 valid responses representing 90\% response rate. In classifying the respondents, 31 household fell under low income earners, 58 under medium income while 19 fell under the high income earners, making a total of 108 respondents. Apart from the above primary source, data were obtained from secondary sources as well; these include the statistical bulletin of Central Bank of Nigeria (CBN), the website of Power Holding Company of Nigeria (PHCN) and relevant literature. 


\subsection{Method of data analysis}

Quantitative data collected in the field were collated and tables showing frequencies of observation were compiled using the statistical package for social science (SPSS) computer program (see tables 4.1, 4.2a, 4.3a, 4.4a, 4.5, 4.5a, 4.6a, 4.7a, 4.8, 4.9a 4.10a and 4.11a).

Fisher's least significant difference (LSD) was used in the analyses:

$\mathrm{LSD}=\mathrm{t}_{\alpha / 2} \sqrt{\operatorname{MSE}\left(\frac{1}{n i}+\frac{1}{n j}\right)}$

Where;

MSE $=$ Mean Squares due to Error

$\mathrm{t}_{\alpha / 2}$ is based on a $\mathrm{t}$ distribution with $\mathrm{n}_{\mathrm{T}}-\mathrm{k}$ degree of freedom

$n_{i}$ and $n_{j}$ are observations.

$\alpha$ - level of significance

Finally, Matlab software package was used to find which of the energy sources is more economical across different classes of income earners. Data were fitted into a model equation (equation 3.2) from Matlab package and used to predict the level of use of the energy sources.

$\mathrm{Y}=\mathrm{a}_{0}+\mathrm{a}_{1} \mathrm{X}_{1}+\mathrm{a}_{2} \mathrm{X}_{2}+\mathrm{a}_{3} \mathrm{X}_{1} \mathrm{X}_{2}+\mathrm{a}_{1} \mathrm{X}_{1}^{2}+\mathrm{a}_{3} \mathrm{X}_{2}^{2}$

$\mathrm{a}_{0}+\mathrm{a}_{1} \mathrm{x}_{1}+\mathrm{a}_{2} \mathrm{x}_{2}=$ Linear part of the equation.

$\mathrm{a}_{3} \mathrm{X}_{1} \mathrm{X}_{2}=$ the interaction part.

$\mathrm{a}_{1} \mathrm{x}_{1}{ }^{2}+\mathrm{a}_{i} \mathrm{X}_{2}{ }^{2}=$ the quadratic part.

\subsubsection{Model Specification}

$\mathrm{Y}=\mathrm{f}\left(\mathrm{x}_{1}+\mathrm{x}_{2}+\mathrm{x}_{1} \mathrm{X}_{2}+\mathrm{x}_{1}{ }^{2}+\mathrm{x}_{2}{ }^{2}\right)$

Where;

$\mathrm{Y}=$ Domestic Energy usage

$\mathrm{x}_{1}=$ Income level

$\mathrm{x}_{2}=$ Source of power

$\mathrm{X}_{1} \mathrm{X}_{2}=$ Interaction of income level and power source.

Matrix form of the equation is:

$\mathrm{a}_{0} \mathrm{n}+\mathrm{a}_{1} \sum \mathrm{x}_{1}+\mathrm{a}_{2} \sum \mathrm{x}_{2}+\mathrm{a}_{3} \sum \mathrm{x}_{1} \mathrm{x}_{2}+\mathrm{a}_{2} \sum \mathrm{x}_{1}{ }^{2}+\mathrm{a}_{5} \sum \mathrm{x}_{2}{ }^{2}=\sum \mathrm{y}$

$\mathrm{a}_{0} \sum \mathrm{x}_{1}+\mathrm{a}_{1} \sum \mathrm{x}_{1}{ }^{2}+\mathrm{a}_{2} \sum \mathrm{x}_{1} \mathrm{x}_{2}+\mathrm{a}_{3} \sum \mathrm{x}_{1}{ }^{2} \mathrm{x}^{2}+\mathrm{a}_{4} \sum \mathrm{x}^{3}+\mathrm{a}_{2} \sum \mathrm{x}_{1} \mathrm{x}_{2}{ }^{2}=\sum \mathrm{yx}_{1}$

$\mathrm{a}_{0} \sum \mathrm{x}_{2}+\mathrm{a}_{1} \sum \mathrm{x}_{1} \mathrm{X}_{2}+\mathrm{a}_{2} \sum \mathrm{x}_{2}{ }^{2}+\mathrm{a}_{3} \sum \mathrm{x}_{1} \mathrm{X}_{2}{ }^{2}+\mathrm{a}_{4} \sum \mathrm{x}_{1}{ }^{2} \mathrm{x}_{2}+\mathrm{a}_{5} \sum \mathrm{x}_{2}{ }^{3}=\sum \mathrm{y}_{2}$

$\mathrm{a}_{0} \sum \mathrm{y}+\mathrm{a}_{1} \sum \mathrm{x}_{1} \mathrm{y}+\mathrm{a}_{2} \sum \mathrm{x}_{2} \mathrm{y}+\mathrm{a}_{2} \sum \mathrm{x}_{1} \mathrm{x}_{2} \mathrm{y}+\mathrm{a}_{2} \sum \mathrm{x}_{1}{ }^{2} \mathrm{y}+\mathrm{a}_{5} \sum \mathrm{x}_{2}{ }^{2} \mathrm{y}=\sum \mathrm{y}^{2}$

$\mathrm{a}_{0} \sum \mathrm{x}_{1}{ }^{2}+\mathrm{a}_{1} \sum \mathrm{x}_{1}{ }^{3}+\mathrm{a}_{2} \sum \mathrm{x}_{1}{ }^{2} \mathrm{x}_{2}+\mathrm{a}_{3} \sum \mathrm{x}_{1}{ }^{3} \mathrm{x}_{2}+\mathrm{a}_{2} \sum \mathrm{x}_{1}{ }^{4}+\mathrm{a}_{5} \sum \mathrm{x}_{1}{ }^{2} \mathrm{x}_{2}{ }^{2}=\sum \mathrm{yx}_{1}{ }^{2}$

$\mathrm{a}_{0} \sum \mathrm{x}_{2}{ }^{2}+\mathrm{a}_{1} \sum \mathrm{x}_{1} \mathrm{x}_{2}{ }^{2}+\mathrm{a}_{2} \sum \mathrm{x}_{2}{ }^{3}+\mathrm{a}_{3} \sum \mathrm{x}_{1} \mathrm{X}_{2}{ }^{3}+\mathrm{a}_{2} \sum \mathrm{x}_{1}{ }^{2} \mathrm{x}_{2}{ }^{2}+\mathrm{a}_{5} \sum \mathrm{x}_{2}{ }^{4}=\sum \mathrm{yx}_{2}{ }^{2}$ 


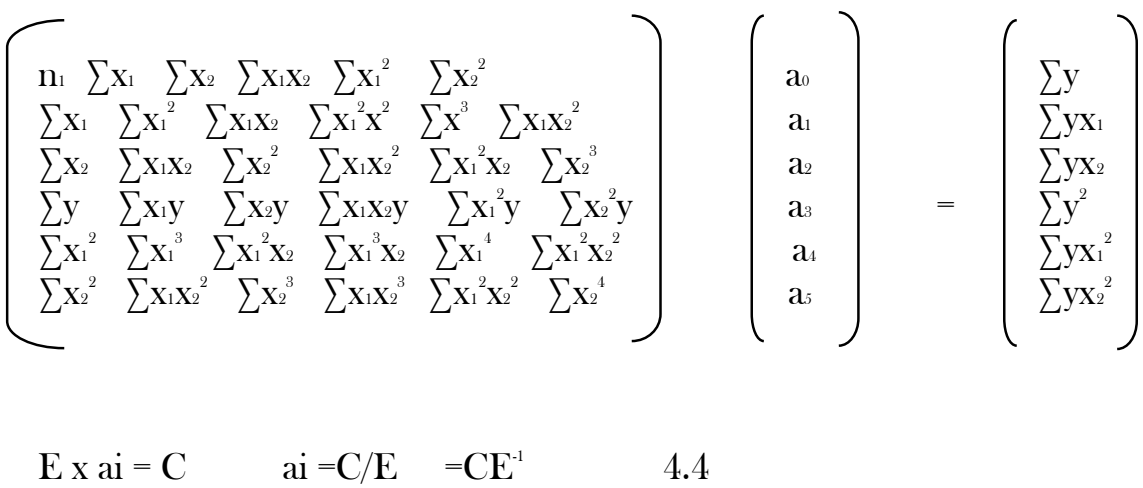

\subsection{Definition of terms used.}

4.5.1 T- stat

This is a ratio of the departure of an estimated parameter from its notional value and its standard error.

Let $\beta$ be an estimator of parameter $\beta$ in some statistical model. Then a t- stat for this parameter is a quantity of the form.

$\mathrm{t}_{\beta}=\frac{\beta-\beta_{\circ}}{\operatorname{s.e}(\beta)} \quad 4.5$

Where $\beta_{0}$ is a non random known constant.

s.e $=$ The standard error of the estimator $\beta$. By default statistical package report t-stat with $\beta_{\mathrm{o}}=\mathrm{o}$ (this t-stat values are used to test the significance of corresponding regressors). However, when t- stat is needed to test the hypothesis of the form Ho: $\beta=\beta_{\circ}$, Then a non zero $\beta_{\circ}$ may be used.

\subsubsection{P value:}

This is the probability that an effect at least as extreme as the current observation has occurred by chance. If P-value is less than or equal to 0.05 it means that there is no more than a 5\% probability of observing a result as extreme as that observed solely due to chance and considered statistically significant.

\subsubsection{F- statistics}

This is a value resulting from a standard statistical test used in ANOVA and regression analysis to determine if the variances between the means of two populations are significantly different. For practical purposes, it is important to know that this value determines the $\mathrm{p}$ - value, but the $\mathrm{F}$ - statistics number will not actually be used in the interpretation here.

\subsubsection{Standard Error (s.e)}

Standard error is the deviation of the sampling distribution of a statistics. It is a statistical term that measures the accuracy with which a sample represents a population. In statistics, samples mean deviates from the actual mean of a population; this deviation is the standard error. The smaller the standard error the more representative the sample will be of the overall population. The s.e is also inversely proportional to the sample size. The larger the sample size, the smaller the s.e because the statistics will approach the actual value.

p- value $\leq 0.05$ (at $5 \%$ confidence)

Rule of thumb: $t$ stat $\geq 2$. The coefficient is significant. 


\subsubsection{Correlation coefficient $\mathbf{R}$ squared $\left(\mathbf{R}^{2}\right)$}

$\mathrm{R}^{2}$ - indicates how well data points fit a statistical model - sometimes simply a line or curve. It is a statistic used in the context of statistical models whose main purpose is either the prediction of future outcomes or the testing of hypotheses, on the basis of other related information.

$\mathrm{R}^{2}=\frac{1-\mathrm{SS}_{\mathrm{res}}}{\mathrm{SS_{ \textrm {tot } }}}$

Where

SThe

$\mathrm{SS}_{\mathrm{res}}=$ Sum of square of residuals

$\mathrm{R}^{2}$ is a measure of fit, Adj $\mathrm{R}^{2}$ is instead a comparative measure of suitability of alternative nested sets of explanators. As such, care must be taken in interpreting and reporting this statistic. Adj $\mathbf{R}^{2}$ is particularly useful in feature selection stage of model building.

\subsubsection{Adjusted R squared (Adj.R ${ }^{2}$ )}

The Adj. $\mathbf{R}^{2}$ compares the explanatory power of regression models that contain different numbers of predictors. The Adjusted $\mathbf{R}^{2}$ is a modified version of $\mathbf{R}^{2}$ that has been adjusted for the number of predictors in the model. The Adj $\mathrm{R}^{2}$ increases only if the new terms improve the model more than would be expected by chance. The Adj $\mathbf{R}^{2}$ can be negative, but it's usually not. It is always lower than the $\mathbf{R}^{2}$

\subsubsection{Decision Rule}

$\mathrm{H}_{\mathrm{o}}=$ Null Hypothesis.

Using test statistics: Reject $\mathrm{H}_{\mathrm{o}}$ if $\mathrm{F}_{\mathrm{CAL}}>\mathrm{F}_{\mathrm{TAB}}$

Where the value of $\mathbf{F}_{\text {TAB }}$ is based on an F-distribution with $k$ - 1 numerator degrees of freedom and $n_{\mathrm{T}}-$ 1denominator degrees of freedom. 


\section{DATA PRESENTATION / DISCUSSION.}

The household questionnaire comprised two main parts: first part consisted of questions addressing the socio-economic characteristics of the respondents and households sampled. This then enabled me to classify them into low income, medium and high income earners, while second part consisted of questions which addressed the pattern of energy used for cooking, appliances and lightening.

A total of 120 questionnaire forms were administered in a random sampling method with 108 valid responses representing $90 \%$ response rate. In classifying the respondents, 31 household fell under low income earners, 58 under medium income while 19 fell under the high income earners making a total of 108 respondents

Quantitative data collected in the field were collated and tables showing frequencies of observation were compiled using the statistical package for social science (SPSS) computer program. Matlab software was also used in the analysis.

Apart from the above primary source, data were obtained from secondary source as well; these include the statistical bulletin of Central Bank of Nigeria (CBN), the website of Power Holding Company of Nigeria (PHCN) and relevant literature.

Fisher's least significant difference (LSD) was used in the analyses:

$\mathrm{LSD}=\mathrm{t}_{\alpha / 2} \sqrt{\operatorname{MSE}\left(\frac{1}{n i}+\frac{1}{n j}\right)}$

Finally matlab software package was used to find which of the energy sources is more economical across different classes of income earners. Data were fitted into a model equation (equation 3.2) from matlab package and used to predict the level of use of the energy sources.

$\mathrm{Y}=\mathrm{a}_{0}+\mathrm{a}_{1} \mathrm{X}_{1}+\mathrm{a}_{2} \mathrm{X}_{2}+\mathrm{a}_{3} \mathrm{X}_{1} \mathrm{X}_{2}+\mathrm{a}_{1} \mathrm{X}_{1}{ }^{2}+\mathrm{a}_{5} \mathrm{X}_{2}{ }^{2}$ 
5.1 Statistical analysis for domestic cooking (low income earners)

With SPSS software the following tables and figure were generated;

Table 5.1a: Amount (\$) spent per household on domestic appliances per month by low income earners.

\begin{tabular}{|c|c|c|c|}
\hline Sample & Electricity & Petrol & Diesel \\
\hline 1 & 2500 & 2000 & 900 \\
\hline 2 & 2300 & 2200 & 1100 \\
\hline 3 & 1500 & 3000 & 1000 \\
\hline 4 & 2400 & 2300 & 800 \\
\hline 5 & 2000 & 2500 & 800 \\
\hline 6 & 2000 & 2400 & 900 \\
\hline 7 & 2500 & 2700 & 1200 \\
\hline 8 & 1800 & 2200 & 950 \\
\hline 9 & 2500 & 2000 & 1200 \\
\hline 10 & 1700 & 2600 & 1000 \\
\hline 11 & 2000 & 2500 & 900 \\
\hline 12 & 1900 & 2250 & 1000 \\
\hline 13 & 1800 & 2000 & 1100 \\
\hline 14 & 2100 & 2250 & 950 \\
\hline 15 & 1700 & 3000 & 800 \\
\hline 16 & 2200 & 2400 & 1100 \\
\hline 17 & 1500 & 2800 & 1000 \\
\hline 18 & 2300 & 2400 & 1200 \\
\hline 19 & 1500 & 2500 & 1200 \\
\hline 20 & 1800 & 2500 & 1200 \\
\hline 21 & 1550 & 2000 & 800 \\
\hline 22 & 1650 & 3000 & 1200 \\
\hline 23 & 1700 & 2100 & 850 \\
\hline 24 & 1700 & 2100 & 900 \\
\hline 25 & 1800 & 2300 & 1100 \\
\hline 26 & 1900 & 2400 & 1200 \\
\hline 27 & 2200 & 2500 & 900 \\
\hline 28 & 2200 & 2500 & 1100 \\
\hline 29 & 2400 & 2200 & 800 \\
\hline 30 & 2300 & 2600 & 850 \\
\hline 31 & 2500 & 2700 & 850 \\
\hline Total & 61900 & 74900 & 30850 \\
\hline Mean & $1996.77^{\mathrm{b}}$ & $2416.13^{a}$ & $995.16^{c}$ \\
\hline
\end{tabular}



$\pm 333.40$ $\pm 291.95$ $\pm 147.40$

All values are expressed as means \pm SD

Means with uncommon superscripts a to $d$ along columns differ significantly at $\mathrm{p}<0.05$ i.e. mean with different superscript are significantly different at $95 \%$ level of confidence.

Diesel with superscript c was more economical than other sources of energy for domestic appliances.

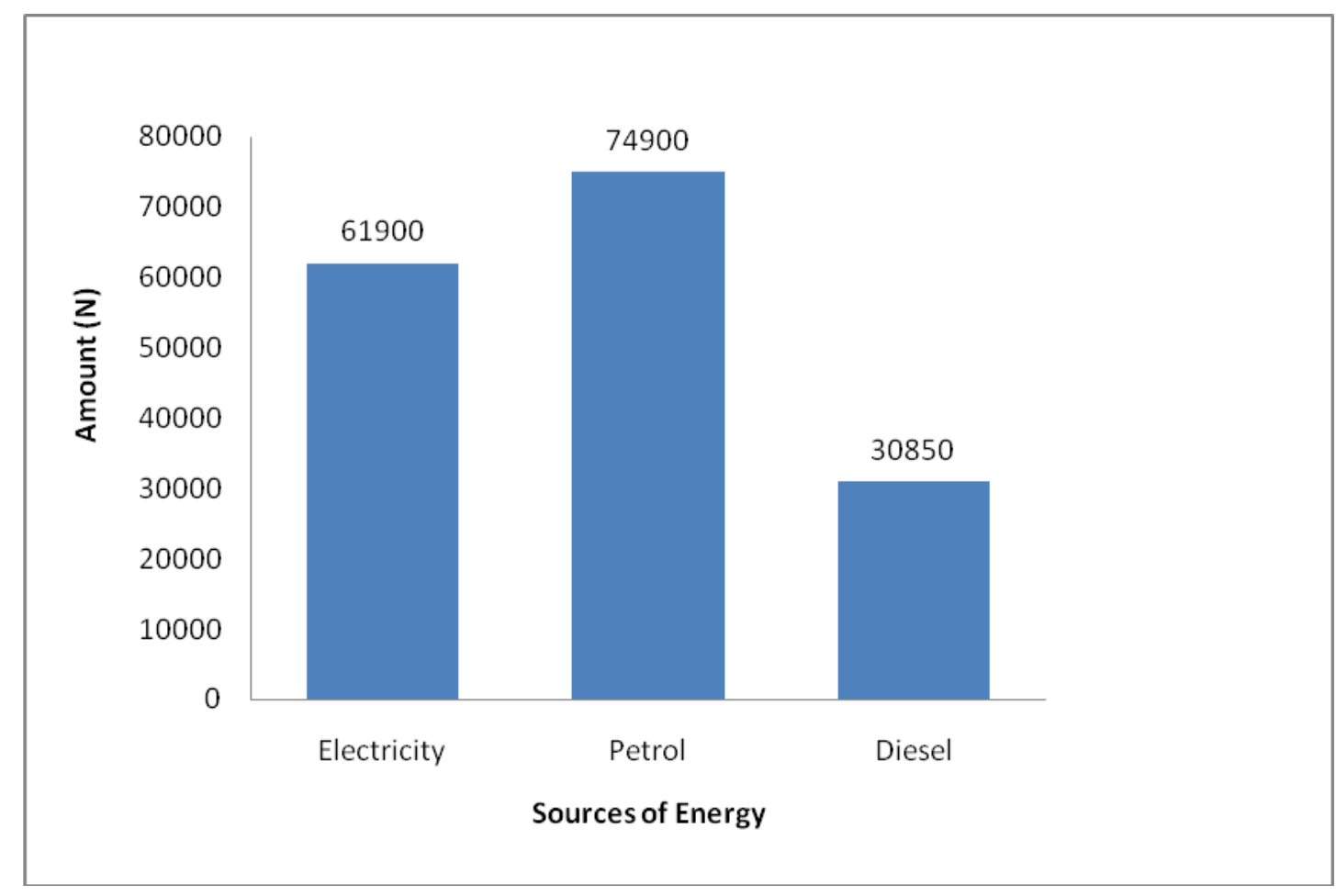

Fig 5.1: Total amount ( spent by households on different energy sources for domestic appliances per month (low income).

Table 5.1b: One - way ANOVA table for domestic appliances per month (low income)

\begin{tabular}{|l|l|l|l|l|l|}
\hline Source of Variation & $\boldsymbol{S S}$ & $\boldsymbol{d f}$ & $\boldsymbol{M S}$ & $\boldsymbol{F}_{C A L}$ & $\boldsymbol{F}_{\text {TAB }}$ \\
\hline Between Groups & 33048441 & 2 & 16524220 & 227.2798 & 3.097698 \\
\hline Within Groups & 6543387 & 90 & 72704.3 & & \\
\hline Total & 39591828 & 92 & & & \\
\hline
\end{tabular}

Decision: Using test Statistics: Reject $\mathrm{H}_{\circ}$ if $\mathrm{F}_{\mathrm{CAL}}>\mathrm{F}_{\mathrm{TAB}}$

Since $\mathrm{F}_{\text {са. }}>\mathrm{F}_{\text {тав, }}$ we reject $\mathrm{H}_{\circ}$ and conclude that there is difference in the source of energy used per household on domestic appliances per month. 


\section{DOMESTIC APPLIANCE ENERGY SOURCE}

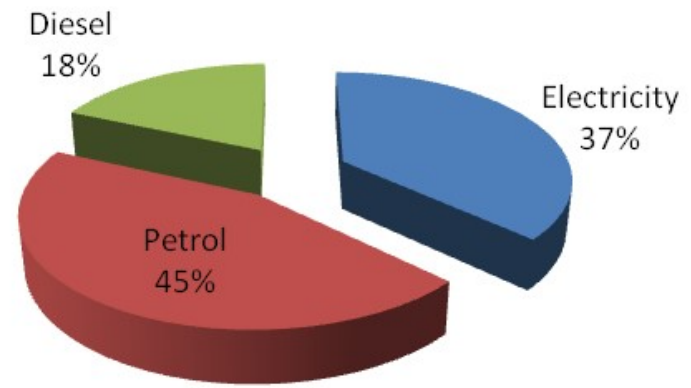

Fig. 5.2 Domestic Appliances Energy Sources in Percent (Low Income).

From fig. 5.2, 45\% of domestic appliances energy source was petrol, followed by electricity with 37\%, and diesel with $18 \%$. The statistical summary in fig 4.6 has shown that petrol was the major source of domestic energy appliance for low income earners. Diesel with $18 \%$ was the least source of power for appliances. This was largely due to the fact that diesel generators are costlier and less common than petrol generators.

Table 5.2a: Amount ( spent per household on domestic appliances per month (By medium income earners).

\begin{tabular}{|l|l|l|l|}
\hline Sample & Petrol & Diesel & Electricity (PHCN) \\
\hline 1 & 5200 & 3600 & 2800 \\
\hline 2 & 4200 & 2550 & 1600 \\
\hline 3 & 4500 & 3000 & 2000 \\
\hline 4 & 5000 & 3400 & 2600 \\
\hline 5 & 5000 & 3500 & 2700 \\
\hline 6 & 4500 & 2800 & 1800 \\
\hline 7 & 4200 & 2500 & 1500 \\
\hline 8 & 5200 & 3600 & 2700 \\
\hline 9 & 4500 & 2700 & 1700 \\
\hline 10 & 4800 & 3200 & 2400 \\
\hline 11 & 5500 & 3800 & 2800 \\
\hline 12 & 4500 & 2700 & 1800 \\
\hline 13 & 4800 & 2800 & 1800 \\
\hline 14 & 6000 & 4000 & 3000 \\
\hline 15 & 6000 & 4000 & 3000 \\
\hline 16 & 4200 & 2500 & 1500 \\
\hline 17 & 5500 & 3800 & 2800 \\
\hline 18 & 4500 & 3000 & 2000 \\
\hline 19 & 4400 & 2700 & 1500 \\
\hline 20 & 4200 & 2400 & 1200 \\
\hline 21 & 4100 & 2300 & 1100 \\
\hline 22 & 4500 & 3000 & 1900 \\
\hline 23 & 4100 & 2300 & 1100 \\
\hline 24 & 5000 & 3500 & 2500 \\
\hline & & & \\
\hline & & & \\
\hline
\end{tabular}




\begin{tabular}{|c|c|c|c|}
\hline Sample & Petrol & Diesel & Electricity (PHCN) \\
\hline 25 & 5500 & 4000 & 2800 \\
\hline 26 & 6000 & 3900 & 3000 \\
\hline 27 & 4800 & 3500 & 2500 \\
\hline 28 & 6000 & 4000 & 3000 \\
\hline 29 & 4800 & 3200 & 2400 \\
\hline 30 & 4300 & 2600 & 1600 \\
\hline 31 & 5000 & 3400 & 2600 \\
\hline 32 & 5500 & 3900 & 2800 \\
\hline 33 & 4500 & 2800 & 1900 \\
\hline 34 & 5200 & 3800 & 2800 \\
\hline 35 & 5000 & 3000 & 2000 \\
\hline 36 & 4100 & 2300 & 1200 \\
\hline 37 & 4300 & 2500 & 1100 \\
\hline 38 & 4200 & 2550 & 1500 \\
\hline 39 & 4800 & 3500 & 2500 \\
\hline 40 & 6000 & 4000 & 3000 \\
\hline 42 & 4200 & 2400 & 1200 \\
\hline 43 & 4200 & 2550 & 1500 \\
\hline 44 & 6000 & 4000 & 3000 \\
\hline 45 & 5300 & 3200 & 2500 \\
\hline 46 & 5200 & 3400 & 2700 \\
\hline 47 & 5000 & 3500 & 2600 \\
\hline 48 & 4100 & 2300 & 1100 \\
\hline 49 & 4800 & 3200 & 2400 \\
\hline 50 & 4500 & 2700 & 1800 \\
\hline 51 & 4100 & 2400 & 1200 \\
\hline 52 & 4500 & 3200 & 2000 \\
\hline 53 & 4300 & 2700 & 1800 \\
\hline 54 & 5200 & 3600 & 2700 \\
\hline 55 & 4200 & 2550 & 1500 \\
\hline 56 & 4300 & 2700 & 1600 \\
\hline 57 & 5500 & 3900 & 2800 \\
\hline 58 & 4500 & 2800 & 1800 \\
\hline Total & 278600 & 180300 & 122300 \\
\hline Mean & $4803.45^{\mathrm{a}}$ & $3108.62^{b}$ & $2108.62^{c}$ \\
\hline SD & \pm 592.63 & \pm 566.55 & \pm 629.75 \\
\hline
\end{tabular}

All values are expressed as means \pm SD

Means with uncommon superscripts a to $\mathrm{c}$ along columns differ significantly at $\mathrm{p}<0.05$ i.e. mean with different superscript are significantly different at 95\% level of confidence. Electricity (PHCN) with superscript c was likely to be more economical than other sources of energy for domestic appliances if available regularly. 
Table 5.2b: One - way ANOVA table for domestic appliances per month (medium income)

\begin{tabular}{|l|l|l|l|l|l|}
\hline Source of Variation & $\boldsymbol{S S}$ & $\boldsymbol{D f}$ & $\boldsymbol{M S}$ & $\boldsymbol{F}_{C A L}$ & $\boldsymbol{F}_{\text {TAB }}$ \\
\hline Between Groups & 215267701.1 & 2 & 107633850.6 & 302.12 & 3.048 \\
\hline Within Groups & 60920689.66 & 171 & 356261.34 & & \\
\hline Total & 276188390.8 & 173 & & & \\
\hline
\end{tabular}

Decision: Using test Statistics: Reject $\mathrm{H}_{\circ}$ if $\mathrm{F}_{\mathrm{CAL}}>\mathrm{F}_{\mathrm{TAB}}$

Since $\mathrm{F}_{\mathrm{CAL}}>\mathrm{F}_{\mathrm{TAB}}$, we reject $\mathrm{H}_{\text {。 }}$ and conclude that there is difference in the source of energy used per household on domestic appliances per month.

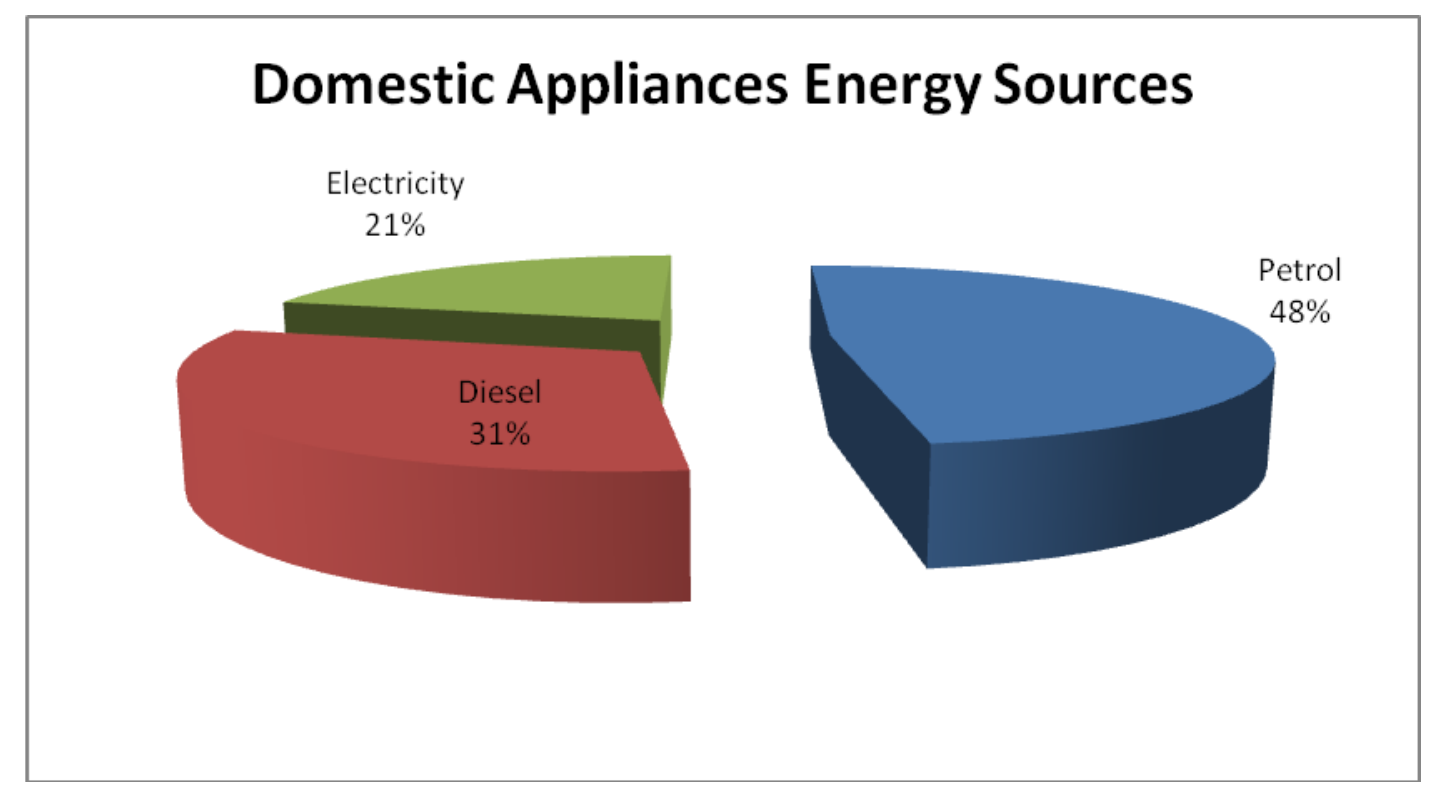

Fig. 5.3: Domestic appliances energy sources (monetary values) in percent (medium income).

Fig 5.3 summarises the cost of energy for domestic appliances by medium income earners sampled as $48 \%$ petrol, $31 \%$ diesel and $21 \%$ electricity (PHCN). 
Table 5.3a: Amount ( spent per household on domestic appliances per month (by high income earners).

\begin{tabular}{|l|l|l|l|}
\hline Sample & Petrol & Diesel & Electricity (PHCN) \\
\hline 1 & 6200 & 4000 & 2300 \\
\hline 2 & 5500 & 3100 & 1100 \\
\hline 3 & 6000 & 3200 & 1700 \\
\hline 4 & 6000 & 3100 & 1500 \\
\hline 5 & 7000 & 3500 & 2200 \\
\hline 6 & 5800 & 3600 & 1500 \\
\hline 7 & 9000 & 4000 & 3000 \\
\hline 8 & 5500 & 3100 & 1200 \\
\hline 9 & 8000 & 4000 & 3000 \\
\hline 10 & 6000 & 3900 & 2000 \\
\hline 11 & 7000 & 3800 & 2500 \\
\hline 12 & 7200 & 3200 & 3000 \\
\hline 13 & 7000 & 3200 & 3000 \\
\hline 14 & 5800 & 3400 & 1400 \\
\hline 15 & 6300 & 3100 & 2800 \\
\hline 16 & 8000 & 3400 & 3000 \\
\hline 17 & 6000 & 3500 & 2300 \\
\hline 18 & 5600 & 3300 & 1300 \\
\hline 19 & 5950 & 3700 & 1600 \\
\hline Total & 123850 & 66100 & 40400 \\
\hline Mean & $6518.42^{\mathrm{a}}$ & $3478.95^{\mathrm{b}}$ & $2126.32^{c}$ \\
\hline SD & \pm 977.70 & \pm 334.30 & \pm 701.46 \\
\hline All & & \\
\hline
\end{tabular}

All values are expressed as means \pm SD

Means with uncommon superscripts a to $\mathrm{c}$ along columns differ significantly at $\mathrm{p}<0.05$ i.e. means with different superscript are significantly different at $95 \%$ level of confidence.

Electricity with superscript c was more economical than other sources of energy for domestic appliances.

Table 5.3b: One -way ANOVA table for domestic appliances per month (high income)

\begin{tabular}{|l|l|l|l|l|l|}
\hline Source of Variation & $\boldsymbol{S S}$ & $\boldsymbol{D} \boldsymbol{M}$ & $\boldsymbol{M S}$ & $\boldsymbol{F}_{C A L}$ & $\boldsymbol{F}_{T A B}$ \\
\hline Between Groups & 192271140.4 & 2 & 96135570 & 184.91 & 3.17 \\
\hline Within Groups & 28074473.68 & 54 & 519897.7 & & \\
\hline Total & 220345614 & 56 & & & \\
\hline
\end{tabular}

Decision: Using test Statistics: Reject $\mathrm{H}_{\mathrm{o}}$ if $\mathrm{F}_{\mathrm{CAL}}>\mathrm{F}_{\mathrm{TAB}}$

Since $\mathrm{F}_{\mathrm{CAL}}>\mathrm{F}_{\mathrm{TAB}}$, we reject $\mathrm{H}_{\circ}$ and conclude that there is significant difference in the source of energy used per household on domestic appliances per month. 


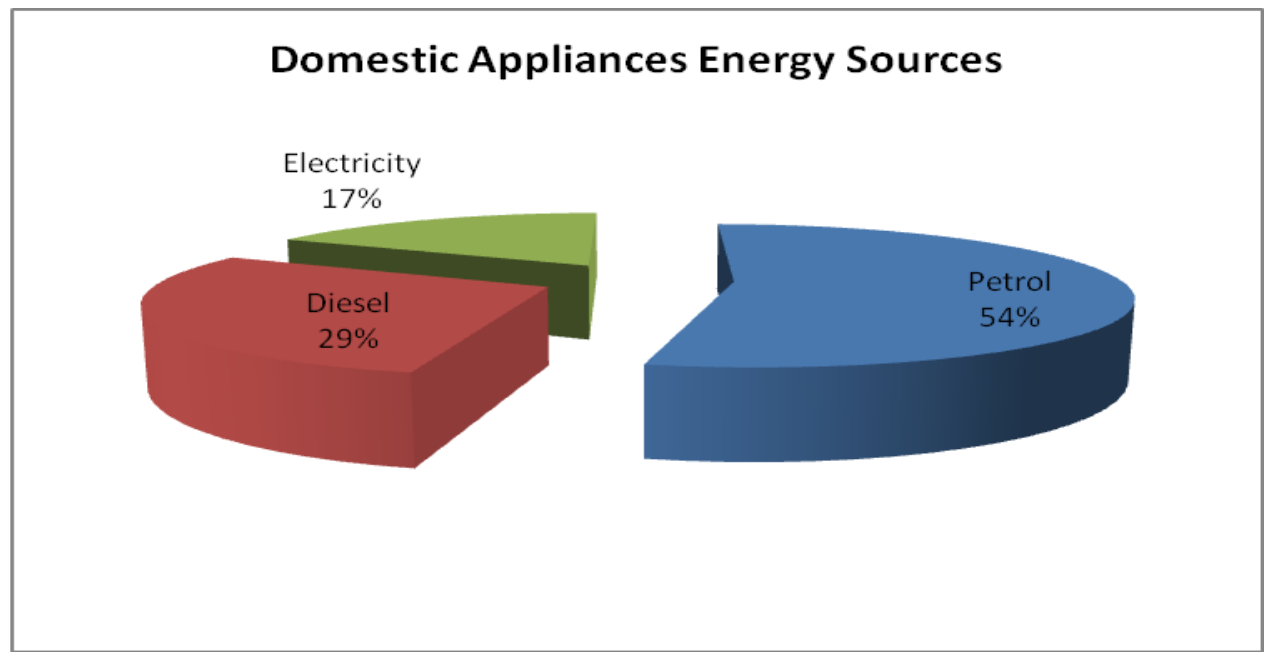

Fig. 5.4: Domestic appliances energy sources (monetary values) in percent (high income).

Fig 5.4 shows that the high income earners spent $54 \%$ on petrol, $29 \%$ on diesel and $17 \%$ on electricity (PHCN) as sources of energy for domestic appliances.

\subsection{Analysis with matlab.}

For domestic appliances; $\mathrm{X} \mathrm{a}_{1}$ represent income level while $\mathrm{X} \mathrm{a}_{2}$ represent source of power.

Low Income $=1$

Middle Income $=2$

High Income $=3$

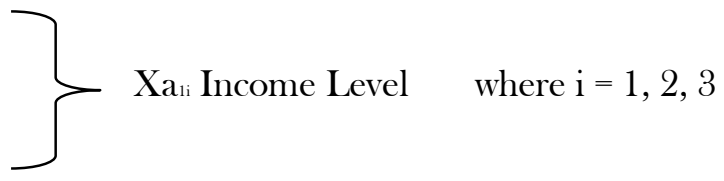

Let low income $=X a_{11}$, Medium income $=X a_{12}$, High income $=X a_{13}$

Sources of power for appliances

Petrol $=1$

Diesel $=2$

Electricity $=3$

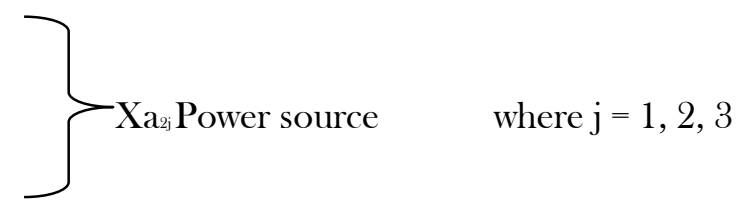

Petrol $=\mathrm{Xa}_{21}$, Diesel $=\mathrm{Xa}_{22}$ and Electricity $=\mathrm{Xa}_{23}$

Table 5.4: Codes with cost (mean) for domestic appliances

\begin{tabular}{|l|l|l|l|l|l|l|l|l|l|}
\hline $\mathrm{Xa}_{1}$ & $\begin{array}{l}1 \\
\left(\mathrm{xa}_{11}\right)\end{array}$ & $\begin{array}{l}1 \\
\left(\mathrm{xa}_{11}\right)\end{array}$ & $\begin{array}{l}1 \\
\left(\mathrm{xa}_{11}\right)\end{array}$ & $\begin{array}{l}2 \\
\left(\mathrm{xa}_{12}\right)\end{array}$ & $\begin{array}{l}2 \\
\left(\mathrm{xa}_{12}\right)\end{array}$ & $\begin{array}{l}2 \\
\left(\mathrm{xa}_{12}\right)\end{array}$ & $\begin{array}{l}3 \\
\left(\mathrm{xa}_{13}\right)\end{array}$ & $\begin{array}{l}3 \\
\left(\mathrm{xa}_{13}\right)\end{array}$ & $\begin{array}{l}3 \\
\left(\mathrm{xa}_{13}\right)\end{array}$ \\
\hline $\mathrm{Xa}_{2}$ & $\begin{array}{l}2 \\
\left(\mathrm{xa}_{21}\right)\end{array}$ & $\begin{array}{l}2 \\
\left(\mathrm{xa}_{22}\right)\end{array}$ & $\begin{array}{l}\left.\mathrm{xa}_{23}\right) \\
\left(\mathrm{xa}_{21}\right)\end{array}$ & $\begin{array}{l}2 \\
\left(\mathrm{xa}_{22}\right)\end{array}$ & $\begin{array}{l}3 \\
\left(\mathrm{xa}_{23}\right)\end{array}$ & $\begin{array}{l}1 \\
\left(\mathrm{xa}_{21}\right)\end{array}$ & $\begin{array}{l}2 \\
\left(\mathrm{xa}_{22}\right)\end{array}$ & $\begin{array}{l}3 \\
\left(\mathrm{xa}_{23}\right)\end{array}$ \\
\hline Cost & 2416.13 & 995.16 & 1996.77 & 4803.45 & 3108.62 & 2108.62 & 6518.42 & 3478.95 & 2126.32 \\
\hline
\end{tabular}

Costs (mean) are from tables 5.1a, 5.2a and 5.3a 
Table 5.5: Model analytical values for domestic appliances

\begin{tabular}{|l|l|l|l|l|l|}
\hline Variables & coefficients & Se & T stat & P val & F statistics \\
\hline $\mathrm{a}_{0}$ & -964.9656 & 2467 & -0.39114 & 0.72182 & $\mathrm{sse}=1.1029 \times 10^{6}$ \\
\hline $\mathrm{a}_{1}$ & $4.4876 \times 10^{3}$ & 1835.7 & 2.4446 & 0.092124 & $\mathrm{dfe}=3$ \\
\hline $\mathrm{a}_{2}$ & -13.7383 & 1835.7 & -0.0074838 & 0.9945 & $\mathrm{dfv}=5$ \\
\hline $\mathrm{a}_{3}$ & -847.6225 & 303.16 & -2.7959 & 0.068082 & $\mathrm{ssv} 2.1661 \times 10^{7}$ \\
\hline $\mathrm{a}_{4}$ & -418.2717 & 428.74 & -0.97559 & 0.40122 & $\mathrm{f}=11.784$ \\
\hline $\mathrm{a}_{5}$ & 90.2233 & 428.74 & 0.21044 & 0.84681 & $\mathrm{Pval}=0.034644$ \\
\hline
\end{tabular}

$\mathbf{R}^{2}=0.9516$

Adj. $\mathbf{R}^{2}=0.8708$

$\mathrm{MSE}=3.6763 \times 10^{5}$

The coefficients of equation 4.2 and other parameters in table 5.5 were obtained by fitting the field data of table 5.4 into that equation.

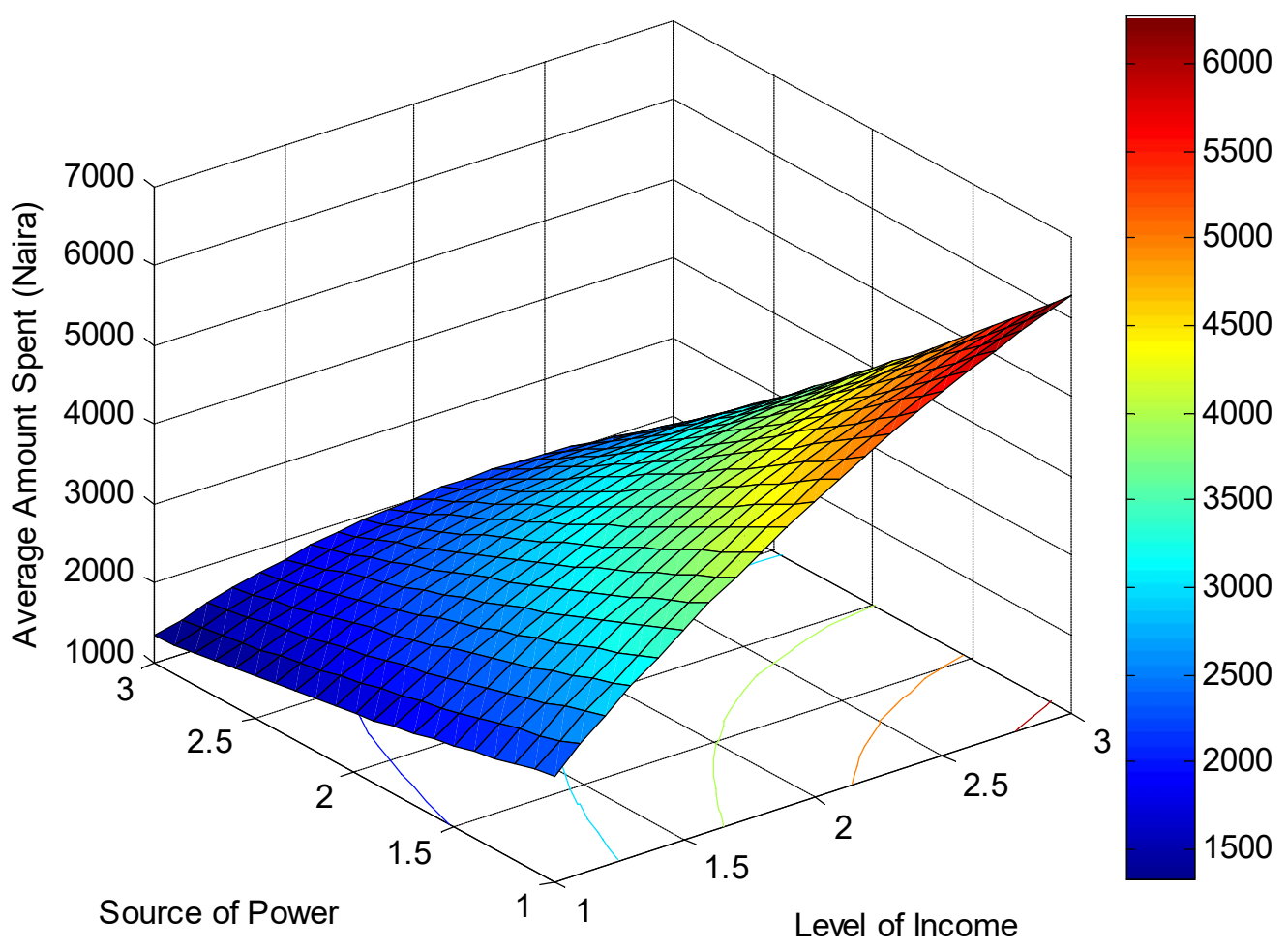

Fig. 5.5: Surface plot for domestic appliances 


\subsection{Model prediction for domestic appliances}

The t-statistics table shows the significance at $90 \%$ confidence of the linear component of level of income, this linear relationship shows up in the surface plot too (Fig. 5.5). Source of power has less effect on amount spent on domestic appliances than it does on domestic cooking and lightening, though the effect is significant at $90 \%$ confidence level. Level of income has effect on amount spent on domestic appliances. The two variables (level of income and source of power) also affect the amount spent on domestic appliance interactively as revealed by the contour of the surface plot (Fig. 5.5). The low income earners (Xa11) using diesel ( $\mathrm{Xa}_{22}$ ) spent the least amount on domestic appliances; the amount is N1332.30 based on the model (equation 4.2) and N995.16 based on table 5.1a. The high income earners $\left(\mathrm{Xa}_{13}\right)$ spent the most amount on domestic appliances using petrol $\left(\mathrm{Xa}_{21}\right)$, the amount is $\mathrm{N} 6267.00$ based on the model and N6518.42 based on table 5.3a.

\section{CONCLUSIONS}

The study on household energy usage for appliances in Owerri metropolitan area revealed the following;

1. The major source of energy for the household in the area is from petroleum products or fossil fuel (petrol, kerosine, gas and diesel).

2. Electrical and other forms of energy consumption were much lower.

3. Renewable energy technologies have not been effectively utilized.

4. There is a strong interaction between source of energy and level of income which invariably determines energy consumption rate.

\section{CONTRIBUTIONS TO KNOWLEDGE}

1. Models were developed for predicting energy usage in domestic appliances.

2. Energy sources for applinces that are preferred by the populace in Owerri metropolis were identified.

3. Predictive model's result was compared with that of experimental data results analysed with a statistical package (SPSS). 
Vol. 7. No. 1, March 2019

\section{REFERENCES}

1. CBN (2004). Statistical Bulletin. Vol. 15 Central Bank of Nigeria. Abuja.

2. Nigeria Energy Study Report. :2005, 'Enabling urban poor livelihood policy making: understanding the role of energy services' University of Twente. Friends of the environment.

3. Nnaji, C. E., Uzoma, C. C. and Chukwu, J. O., (2012). Analysis of factors determining fuelwood use for cooking by rural households in Nsukka area of Enugu State, Nigeria. Continental J. Environmental Sciences. 6(2): 1-6. http://www.wiloludjournal.com.

4. www.ngex.com/nigeria/places/states/imo.htm 